\title{
Intravenous immunoglobulin in HIV infection: evidence for the efficacy of treatment
}

\author{
R A HAGUE, ${ }^{*} \mathrm{P}$ L YAP, ${ }^{*} \mathrm{~J}$ Y Q MOK, $\dagger \mathrm{O}$ B EDEN, $\ddagger \mathrm{N}$ A COUTTS, $\S \mathrm{J}$ G WATSON, \\ F D HARGREAVES, $\uparrow$ AND J M WHITELAW
}

${ }^{*}$ Edinburgh and South East Scotland Blood Transfusion Service; †City Hospital and $\ddagger$ Royal Hospital for Sick Children, Edinburgh; \$Royal Inverclyde Hospital, Greenock; \|Newcastle General Hospital; and IMRC Clinical and Population Cytogenetics Unit, Western General Hospital, Edinburgh

SUMMARY Eight children with symptoms of HIV infection were treated for 12-26 months (median 14 months) with infusions of intravenous immunoglobulin $(200 \mathrm{mg} / \mathrm{kg})$ every three weeks. Significant improvement was noted in all children in terms of weight gain, number of infectious episodes, and days spent in hospital. This resulted in a $49 \%$ saving in cost on treatment compared with costs accrued previously during inpatient admissions. Immunoglobulin concentrations, which were raised at the start of treatment were not altered, and T4 counts continued to decline slowly. HIV core antigen was detected in four children before treatment, but all became core antigen negative after treatment was commenced, this effect being sustained in three. Intravenous immunoglobulin therefore has major clinical benefit, and by reducing viral activity may delay disease progression.

HIV infection in infants and children is associated with high morbidity and mortality, ${ }^{1}$ and present therapeutic options are limited to treatment for specific infections, ${ }^{2}$ and to zidovudine, which has many documented side effects and unknown long term sequelae. ${ }^{3}$ As in adults, these infants may present with opportunistic infections and features suggestive of deficiencies of cellular immunity, with reversed $\mathrm{T} 4 / \mathrm{T} 8$ ratios. ${ }^{45}$ In addition, however, children commonly present with recurrent bacterial infections, ${ }^{16}$ and defective humoral immunity has been shown. ${ }^{7}$ Although serum concentrations of $\operatorname{IgG}, \operatorname{IgA}$, and $\operatorname{IgM}$ are typically raised, ${ }^{8}$ panhypogammaglobulinaemia has been described. ${ }^{9-11}$ Even in the presence of hypergammaglobulinaemia, which is attributed to polyclonal B cell activation, ${ }^{12}$ patients behave as though they were hypogammaglobulinaemic. Hence passive immunisation in the form of intravenous immunoglobulin has been reported to be of benefit. ${ }^{1.3} 1+$ The aim of this study, therefore, was to make a fuller evaluation of the clinical effect of at least 12 months' treatment, to document any changes in laboratory indices of viral activity, and to assess the financial implications of committing children to maintenance treatment with intravenous immunoglobulin.

\section{Patients and methods}

Eight patients with clinical and laboratory evidence of HIV infection were identified, five of whom have been described in a preliminary report. ${ }^{15}$ Clinical features at the start of intravenous immunoglobulin treatment are summarised in table 1 . Children were treated with intravenous immunoglobulin on the basis of a history of two or more episodes of bacterial pneumonia, a three month history of recurrent or chronic upper respiratory tract sepsis or diarrhoea, or both, or symptomatic thrombocytopenia, with laboratory confirmation of HIV infection. All were treated every three weeks with $200 \mathrm{mg} / \mathrm{kg}$ of intravenous immunoglobulin supplied by Scottish National Blood Transfusion Service on a hospital day patient basis. ${ }^{16}$

The procedure and laboratory methods adopted at each visit were as previously described. ${ }^{17}$

The financial implications were calculated on the basis that the cost of intravenous immunoglobulin for a $15 \mathrm{~kg}$ child is $£ 45$ and materials, medical, nursing, and administrative staff time is $£ 40$; this gives a total of $£ 85$ per visit, or $£ 1600$ per year. The cost of inpatient paediatric care in south east Scotland is $£ 960$ per week. ${ }^{18}$ 
Table 1 Clinical data

\begin{tabular}{|c|c|c|c|c|c|}
\hline $\begin{array}{l}\text { Patient } \\
\text { No }\end{array}$ & $\begin{array}{l}\text { Mode of } \\
\text { transmission }\end{array}$ & $\begin{array}{l}\text { Age at } \\
\text { start (months) }\end{array}$ & $\begin{array}{l}\text { Time on } \\
\text { intravenous immuno- } \\
\text { globulin (months) }\end{array}$ & Stage* & Clinical features \\
\hline 1 & Vertical & 9 & 26 & $\mathrm{P} 2 \mathrm{~A}$ & $\begin{array}{l}\text { Recurrent upper respiratory sepsis, diarrhoea, } \\
\text { eczema, failure to thrive }\end{array}$ \\
\hline 2 & Vertical & 24 & 23 & $\mathrm{P} 2 \mathrm{~A}$ & $\begin{array}{l}\text { Recurrent upper respiratory sepsis, recurrent } \\
\text { pneumonia, diarrhoea }\end{array}$ \\
\hline 3 & Vertical & 27 & 17 & P2B & $\begin{array}{l}\text { Prolonged pertussis, encephalopathy, recurrent } \\
\text { pneumonia, diarrhoea }\end{array}$ \\
\hline 4 & Vertical & 48 & 17 & P2D3 & $\begin{array}{l}\text { Recurrent pneumonia, diarrhoea, oesophageal } \\
\text { candida, failure to thrive }\end{array}$ \\
\hline 5 & Blood transfusion & 42 & 16 & $\mathrm{P} 2 \mathrm{C}$ & $\begin{array}{l}\text { Purpura, pneumonia, oral candida, lympho- } \\
\text { cytic interstitial pneumonitis }\end{array}$ \\
\hline 6 & Vertical & 26 & 14 & $\mathrm{P} 2 \mathrm{C}$ & $\begin{array}{l}\text { Upper respiratory sepsis, recurrent pneu- } \\
\text { monia, lymphocytic interstitial pneumonitis, } \\
\text { eczema }\end{array}$ \\
\hline 7 & Vertical & 36 & 14 & $\mathrm{P} 2 \mathrm{~F}$ & $\begin{array}{l}\text { Purpura, night sweats, upper respiratory sepsis, } \\
\text { pneumonia, eczema }\end{array}$ \\
\hline 8 & Vertical & 12 & 12 & $\mathrm{P} 2 \mathrm{~F}$ & $\begin{array}{l}\text { Purpura, recurrent fever, upper respiratory } \\
\text { tract sepsis, eczema }\end{array}$ \\
\hline
\end{tabular}

${ }^{*}$ Stage according to the Centers for Disease Control criteria. ${ }^{25}$

\section{Results}

After 12 months on treatment subjective improvement in general well being was reported in all eight patients. Case 3 showed an initial dramatic improvement in his encephalopathy, as previously described, ${ }^{19}$ but later deteriorated to become severely handicapped before finally succumbing to a pneumonic illness 17 months into treatment. The other seven children remain well enough to attend normal school $(n=2)$ or nursery $(n=5)$ regularly. Table 2 summaries clinical findings before and after treatment. The number of infections sufficiently severe to require hospital review was significantly reduced on treatment, as was recurrent diarrhoea. Improvement in weight gain was seen in the cohort as a whole $(\mathrm{p}<0.01)$; the most dramatic change was seen in those children in whom failure to thrive had been a presenting feature.
The total number of days spent in hospital for all eight children in the 12 months before treatment (except for case 1 in whom only nine months from birth had elapsed) was 220 (range 0-60), compared with 56 (range 0-20) in the first 12 months on intravenous immunoglobulin $(\mathrm{p}<0.001)$. Assuming an unchanged rate of infection, the difference between actual and expected number of days of hospitalisation would be $181 \cdot 6$; this would result in a saving on inpatient costs of $£ 24905$ compared with treatment costs of $£ 12800$. Thus the net saving in costs of $£ 1513 /$ patient/year, or $49 \%$, even without taking into consideration the travelling costs and time lost to the family in attending hospital.

Symptomatic thrombocytopenia, seen in three patients before treatment showed no immediate improvement on this dose of intravenous immunoglobulin, and a further child developed purpura while on treatment. Hypergammaglobulinaemia,

Table 2 Clinical outcome after treatment

\begin{tabular}{llll}
\hline & Before (median) & After (median) & $p$ Value \\
\hline Range of weight velocity (g/month) & -212 to $+312(117)$ & 150 to $582(300)$ & $<0 \cdot 01^{*}$ \\
Total No of serious infectious episodes & $34(3)$ & $6(1)$ & $<0 \cdot 05^{*}$ \\
Total No of episodes of pneumonia & $13(2)$ & $4(0)$ & NS \\
Total months of recurrent or chronic diarrhoea & $49(9)$ & $21(3)$ & $<0 \cdot 05^{*}$ \\
No of patients with: & 8 & 8 & NS \\
Upper respiratory tract sepsis & 5 & 5 & NS \\
Eczema & 8 & 6 & NS \\
Significant lymphadenopathy & 7 & 8 & NS \\
Hepatosplenomegaly & 3 & 2 & NS \\
Thrombocytopenic purpura &
\end{tabular}

${ }^{*}$ Comparison of symptoms and signs experienced by the cohort in the 12 months before and in the subsequent 12 months after treatment. 
seen in all patients before treatment, was not appreciably changed by treatment, and $\mathrm{T} 4$ counts continued to decline (mean (SD) T4 count at the start of treatment was $1.75(0.5) \times 10^{9} / \mathrm{l}$, falling to $1 \cdot 10(0 \cdot 31) \times 10^{9} / 1$ at 1 year, and $0.65(0 \cdot 45) \times 10^{9} / 1$ at 18 months).

All patients were HIV seropositive by enzyme linked immunoadsorbent assay (ELISA) and virus was isolated in culture from all eight. Four children (cases 1, 2, 4, 8) were antigenaemic and anti-p24 core antibody negative before the start of treatment. Changes in antigen concentration after commencing treatment are shown in the figure, anticore antibody concentrations changing in a reciprocal manner. Loss of antigen was sustained in three children, but case 4 , who had much more advanced disease on starting treatment, became antigenaemic again nine months into treatment. Three children (cases 3, 5, 6) have been consistently antigen negative, and in one child (case 7) insufficient data was available before the start of treatment, but 12 months after treatment he is core antigen positive $(>750$ $\mathrm{IU} / \mathrm{ml})$.

Treatment was well tolerated in all children. One child developed a brief encephalopathic episode, with aphasia and confusion during one infusion, over a year after commencing treatment. This was attributed to hyperviscosity, and he has had further infusions at a slower rate without incident. No other side effects have been observed.

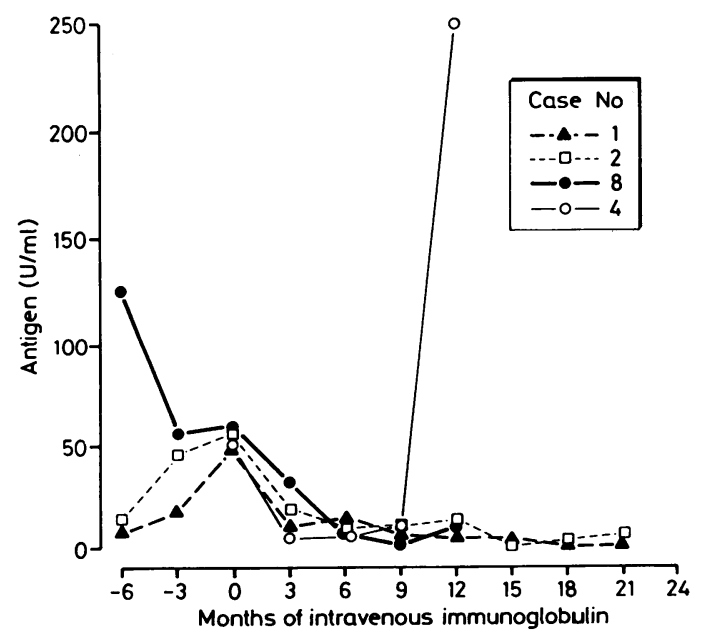

Figure Sequential antigen concentrations in the four children who were antigenaemic before treatment with intravenous immunoglobulin expressed as Abbott units (positive $>20$ ).

\section{Discussion}

Anecdotal evidence of the benefits of intravenous immunoglobulin treatment after short periods of follow up has been reported previously by a number of groups using regimens varying from $200 \mathrm{mg} / \mathrm{kg}$ monthly ${ }^{14}$ to $300 \mathrm{mg} / \mathrm{kg}$ every two weeks. All show reduction in febrile episodes and number of bacterial infections. A more detailed analysis of clinical effect is provided by Schaad et al, ${ }^{20}$ but the length of follow up was limited to only six months in four of the seven children described. Oleske $e t$ al in a larger but non-randomised study suggest that mortality is decreased. ${ }^{14}$ Calvelli and Rubenstein ${ }^{13}$ and Gupta $e t a l^{21}$ have also noted changes in T cell and cell mediated immune function in vivo. In all studies, however, interpretation of results is hampered by the small numbers involved and the lack of control data. Because of the limited treatment options, and the small number of children involved in our study, we felt an untreated control group was not appropriate. Because we have followed up these children prospectively from the time of their diagnosis as being HIV positive, however, we have reliable sequential data for a comparable 12 month period immediately before treatment was commenced. This enables us to use each patient before treatment as his own control, given that the natural history of the disease is one of deterioration in the absence of intervention. In addition, no previous group has documented changes in core antigen and antibody concentrations after treatment, nor have the financial implications been assessed.

Our group showed a great deal of heterogeneity in terms of age, duration, and severity of symptoms before treatment, posing difficulties when analysing the cohort as a whole. These were partly overcome by using the patient as his own control, and also, for example, by standardising growth data in terms of velocities. The choice of our dosage regimen aiming to provide the optimum benefit with minimum distress for the child was based upon data from treatment of primary hypogammaglobulinaemia ${ }^{16}$ It is possible, however, that higher doses may be required more frequently in hypergammaglobulinaemic patients, as the half life of immunoglobulin is reduced at higher serum concentrations. This issue of optimal dosage will only be resolved by further studies of efficacy.

Disappearance of core antigen has been described in adults after the infusion of plasma high in anti-p24 antibody and neutralising capacity has been described previously. ${ }^{22}$ No studies of normal immunoglobulin treatment have documented changes in core antigen, and in view of the small numbers 
involved, further studies will be required to verify these findings. The mechanism is likely to be very different, as plasma donors are screened for HIV infection and the intravenous immunoglobulin preparation has no anti-HIV antibody. It has been suggested that the production of HIV antigen is an indicator of enhanced expression of viral genes, ${ }^{23}$ and may reflect the expression of latent virus after activation of helper $T$ cells. Bacterial and viral infection increase $T$ cell activation, and the disappearance of p24 antigen after commencing treatment may be due to the reduction of viral activation after the decrease in infective episodes. The continued decline in the T4 count was disappointing, but the disappearance of core antigen with intravenous immunoglobulin treatment suggests that the progression to AIDS may be delayed, as the loss of anti-p24 antibody and the appearance of core antigen are recognised bad prognostic signs. ${ }^{24}$

The clinical benefit of treatment we have shown, together with the quality of life enjoyed by our patients, leads us to conclude (in agreement with Schaad's group ${ }^{19}$ ) that there is no case for withholding intravenous immunoglobulin treatment in symptomatic children. This precludes a double blind placebo controlled trial at this stage, although further studies may be necessary to optimise the dose regimen. What remains unclear, however, is at what point in the course of disease treatment should be commenced, given that five of our children were in the early stages of symptomatic disease (CDC P2 $\mathrm{A} / \mathrm{F}){ }^{25} \mathrm{~A}$ controlled trial will be necessary if we are to consider treatment in asymptomatic children. This is liable to be problematic, however, because at present there is still no reliable diagnostic test of HIV infection in young children. As the problem of HIV infection in children grows over the next few years, routine intravenous immunoglobulin treatment has major implications in budgeting of hospital inpatient and day care facilities. We have shown the cost benefit of treatment-at least in the short and medium term. In is unlikely, however, that intravenous immunoglobulin will delay progression indefinitely, and further advances in immunotherapy, such as the introduction of specific antiHIV neutralising antibody in combination with intravenous immunoglobulin and anti-retroviral treatment, will be required if we are to improve the ultimate prognosis for HIV infected children.

$\mathbf{R}$ Hague is a clinical research fellow funded by the Medical Research Council. We would also like to thank the AIDS Virus Education and Research Trust for financial support, Dr Paul Williams for his help at the initiation of the study, Dr J Peutherer and Mrs S Rebus and the University of Edinburgh department of virology for performing the HIV isolation, and the general manager of the Common Services Agency of the Scottish Health Service for the financial support provided.

\section{References}

${ }^{1}$ Scott GB, Buck WE, Leterman JG, et al. Acquired immunodeficiency syndrome in infants. $N$ Engl $J$ Med 1984;310:76-81.

2 Young LS. Treatable aspects of infection due to human immunodeficiency virus. Lancet 1987;ii:1503-6.

${ }^{3}$ Fischl MA, Richmann DD, Grieco MH, et al. The efficacy of azidothymidine (AZT) in the treatment of patients with AIDS and AIDS related complex: a double blind, placebo controlled trial. N Engl J Med 1987;317:185-91.

${ }^{4}$ Minkoff $\mathrm{H}$, Nanda D, Menez R, et al. Pregnancies resulting in infants with acquired immunodeficiency syndrome or AIDS related complex: follow-up of mothers, children and subsequently born siblings. Obstet Gynecol 1987;69:288-9.

5 Rubenstein A, Sicklick M, Gupta A, et al. Acquired immunodeficiency with reverse T4/T8 ratios in infants born to promiscuous and drug-addicted mothers. JAMA 1983;249:2350-6.

${ }^{6}$ Bernstein LJ, Krieger BZ, Novick B, et al. Bacterial infections in the acquired immunodeficiency syndrome of children. Pediatr Infect Dis 1985;4:472-5.

${ }^{7}$ Bernstein LJ, Ochs HD, Wedgwood RJ, et al. Defective humoral immunity in pediatric acquired immune deficiency syndrome. J Pediatr 1985;107:352-7.

8 Ammann AJ. The acquired immunodeficiency syndrome in infants and children. Ann Intern Med 1985;103:734-7.

9 Maloney MJ, Guill MF, Wray BB, et al. Pediatric acquired immune deficiency syndrome with panhypogammaglobulinaemia. J Pediatr 1987;110:266-7.

10 Pahwa R, Good RA, Pahwa S. Prematurity, hypogammaglobulinaemia and neuropathology with human immunodeficiency virus (HIV) infection. Proc Natl Acad Sci USA 1987;84:3826-30.

11 Espanol T, Garcia-Arumi R, Bofill A, et al. Hypogammaglobulinaemia and negative anti-HIV antibodies in AIDS. Arch Dis Child 1987;62:853-4.

12 Zolla-Pazner S. Immunologic abnormalities in infection with the human immunodeficiency virus. Laboratory Medicine 1986;17: 685-9.

13 Calvelli TA, Rubinstein A. Intravenous gammaglobulin in infant acquired immunodeficiency syndrome. Pediatr Infect Dis 1986;5:S207-10.

14 Oleske JM, Connor EM, Bohila R, et al. The use of IV IgG in children with AIDS. Vox Sang 1987;52:162-75.

15 Williams PE, Hague RA, Yap PL, et al. Treatment of human immunodeficiency virus antibody positive children with intravenous immunoglobulin. J Hosp Infect 1988;12 (supp D):67-73.

${ }^{16}$ Leen CLS, Yap PL, McClelland DBL. Increase of serum immunoglobulin level into the normal range in primary hypogammaglobulinaemia by dosage individualisation of intravenous immunoglobulin. Vox Sang 1986;51:278-86.

17 Mok JYQ, Hague RA, Yap PL, et al. The management of children born to HIV seropositive women. $J$ Infect 1989;18: $119-24$.

${ }^{18}$ Common Services Agency of the Scottish Health Service. Scottish health service costs, year ending 31st March 1988. Edinburgh: Public Treasurer's Department, Lothian Health Board.

19 Matthes J, Walker LA, Watson JG, et al. AIDS encephalopathy with response to treatment. Arch Dis Child 1988;63:545-7.

20 Schaad UB, Gianella-Borradori A, Perret B, et al. Intravenous immune globulin in symptomatic paediatric human immunodeficiency virus infection. Eur J Paediatr 1988;147:300-3.

21 Gupta A, Novick B, Rubinstein A. Restoration of suppressor Tcell functions in children with AIDS following intravenous gamma globulin treatment. Am J Dis Child 1986;140:143-6. 
1150 Hague, Yap, Mok, et al

22 Jackson GG, Perkins JT, Rubenis M, et al. Passive immunoneutralisation of HIV in patients with advanced AIDS. Lancet 1988;ii:647-52.

${ }^{23}$ Nabel GJ. Activation of human immunodeficiency virus. $J$ Lab Clin Med 1988;111:495-500.

${ }^{24}$ Lange JMA, Paul DA, Huisman HG, et al. Persistent HIV antigenaemia and decline of HIV core antibodies associated with transition to AIDS. $\mathrm{Br}$ Med J 1986;293:1459-62.
${ }^{25}$ Centers for Disease Control. Classification system for human immunodeficiency virus (HIV) infection in children under 13 years of age. MMWR 1987;36:225-30.

Correspondence to Dr RA Hague, Infectious Diseases Unit, City Hospital, Greenbank Drive, Edinburgh EH10 5SB.

Accepted 10 February 1989 